\title{
“QUE EL QOMLE'EC, EL TOBA, NO ES CUALQUIER COSA...”: LA ENSEÑANZA DEL QOM EN EL ÁREA EDUCATIVA DE UNA MISIÓN PROTESTANTE DESTINADA A INDÍGENAS DEL NOROESTE DEL CHACO (ARGENTINA, 1960-1970)
}

\author{
"Qomle'ec, toba, is not just anything..." The teaching of qom language in \\ the educational area of a protestant mission for indigenous peoples from \\ northwestern Chaco (Argentina, 1960-1970)
}

\author{
Victoria Soledad Almirón* \\ https://orcid.org/0000-0002-3790-3698 \\ David García** \\ https://orcid.org/0000-0001-5320-7644 \\ Yamila Liva*** \\ https://orcid.org/0000-0003-0809-8498
}

\section{Resumen}

El nutrido desarrollo del campo de la historia de la cultura escrita en América Latina nos acerca a la comprensión de la relación histórica de los pueblos indígenas con la cultura letrada que, desde la época de la conquista y colonización, ha sido usada como herramienta de negociación y resistencia. El presente artículo aporta a este campo de discusiones a nivel local, en una temática poco explorada en la Argentina y en la historia reciente. Particularmente, nos interesa describir procesos de enseñanza de prácticas de lectura y escritura en lengua qom, en el marco de las acciones desarrolladas entre las décadas de 19601970 por misioneros protestantes en el noroeste de la provincia del Chaco (Argentina). Reconstruimos en clave histórica el contexto institucional, las orientaciones de la política de alfabetización y las condiciones materiales que viabilizaron que indígenas qom de la región se apropiaran de prácticas de lectura y escritura en el idioma nativo. Como fuentes principales, se recurre al análisis de textos utilizados para la alfabetización, documentos institucionales y entrevistas en profundidad.

$$
<\text { Cultura escrita }><\text { Lengua nativa }><\text { Qom }><\text { Misión protestante }>
$$

\footnotetext{
Abstract

The rich development in the field of the History of Written Culture in Latin America brings us closer to understanding the historical relationship of indigenous peoples with the literate culture. It has

* Becaria Postdoctoral del Consejo Nacional de Investigaciones Científicas y Técnicas (CONICET), Instituto de Investigaciones Geohistóricas (IIGHI), Resistencia, Argentina, sol.almiron@live.com.ar

** Integrante de la Fundación Napalpí y Asesor del Programa Pueblos Indígenas de la Universidad Nacional del Nordeste (UNNE), Resistencia, Argentina, davidgarcia390@hotmail.com

***Becaria Posdoctoral del Consejo Nacional de Investigaciones Científicas y Técnicas (CONICET), Instituto de Investigaciones en Educación, Universidad Nacional del Nordeste (UNNE), Resistencia, Argentina, yamilaliva@gmail.com
} 
Almirón, García y Liva. “Que el qomle’ec, el toba, no es cualquier cosa...”: la enseñanza del qom en e el ámbito...

been used as a tool of negotiation and resistance since the time of conquest and colonization. This article is a contribution to the local field discussions, in a topic little explored in Argentina and in recent history. In particular, we are interested in describing teaching processes of reading and writing practices in the Qom language, within the framework of actions carried out during the decades of 1960 and 1970 by Protestants in the northwest of Chaco (Argentina). We perform an historical reconstruction of the institutional context, the literacy policy orientations and the material conditions that made possible for the Qom people of the region to appropriate reading and writing practices in their native language. The main sources used are the analysis of literacy texts, institutional documents and in-depth interviews.

$<$ Written culture $><$ Native language $><$ Qom $><$ Protestant Mission $>$

Recibido: 04/03/2021 // Aceptado: 21/05/2021

\section{Introducción}

En América Latina encontramos un nutrido corpus de estudios que permiten focalizarnos, desde distintas dimensiones o componentes, en la comprensión de la compleja relación de los pueblos indígenas con la cultura escrita en perspectiva histórica. La historia de la cultura escrita (en adelante HCE), con aportes provenientes de la historiografía, la historia de la educación y la antropología, es uno de los principales campos de contribución con indagaciones referidas a: la historia de apropiación indígena de la cultura escrita; los ámbitos o contextos de difusión de la lectura y/o escritura; las políticas de alfabetización; los materiales usados para alfabetizar; el análisis del idioma de entrada a lo escrito (Almiron, 2019; Almiron y Padawer, 2020; Almiron, Padawer y Artieda, 2017; Artieda, 2012; Escalante Fernández, 2014, 2013; Neunmann, 2015; Rockwell, 2008, 2006, 2004, 2001). En este último caso, resultan fundamentales los aportes y cruces interdisciplinarios con la lingüística.

Estas indagaciones permiten revisar las nociones teóricas antropológicas clásicas (Mc Luhan, 1969; Lévi-Strauss, 1964; Goody, 1986; Ong, 1987) que asistieron a la construcción de descripciones y teorizaciones de carácter dicotómico y divisorias entre oralidad/escritura, así como, relacionalmente, tipificaciones sociales y culturales: culturas orales/culturas letradas; sociedades tradicionales/sociedades civilizadas; pensamiento abstracto-racional/pensamiento en torno a la oralidad y escritura. Desde otra dimensión, permiten replantear la mirada historiográfica que representó a los indígenas como sociedades ágrafas e invisibilizó sus prácticas letradas que, desde la época de la conquista y colonización, han sido usadas como herramientas de negociación y resistencia. Asimismo, contribuyen a dar cuenta acerca de cómo han sido una continuidad histórica las discusiones lingüísticas en torno al uso, la omisión o el desplazamiento de las lenguas nativas en diversos contextos y ámbitos. Entre ellos, el educativo y religioso, estrechamente relacionados con la difusión de la cultura escrita entre indígenas de América Latina.

El artículo se inscribe en la HCE y es un aporte a este campo de discusiones a nivel local, atendiendo a una temática poco explorada en la Argentina y en la historia reciente. Particularmente, nos interesa describir procesos de enseñanza de las prácticas 
de lectura y escritura en lengua qom, en el marco de las acciones desarrolladas entre las décadas de 1960-1970 por una misión protestante asentada en el noroeste de la provincia del Chaco (Argentina) ${ }^{1}$. En cuanto a la metodología, nos centramos en el análisis de los soportes materiales de enseñanza como fuentes de análisis histórico, los cuales permiten evidenciar los sentidos de las políticas de alfabetización y la norma oficial (Chartier, 2005). Con el resguardo de construir interpretaciones que tiendan a establecer una transferencia directa entre los protocolos de lectura de los libros y las prácticas docentes, buscamos hallar indicios de las maneras de escribir en sus aspectos formales y de las situaciones de escritura posibles (Petrucci, 2002). Siguiendo a Rockwell (2001, 2004), el estudio de la materialidad no sólo implica examinar características propias del libro sino también el entorno más general (por ej. la "vida del aula") y la disponibilidad de esos materiales: dónde se encuentran, quiénes controlan su lectura, en qué espacio se lee normalmente y de qué manera.

En este artículo, las cartillas de alfabetización representan textos paradigmáticos usados para la enseñanza de la lectura y la escritura, así como medios vehiculizadores de una política lingüística que ubicaba al idioma nativo como contenido educativo destinado a indígenas de la región en décadas previas al surgimiento de la Educación Bilingüe Intercultural. Nos interesa realizar una reconstrucción historiográfica a partir del uso de fuentes históricas, escritas y visuales. Como adelantamos, principalmente analizamos los soportes utilizados para la enseñanza en qom, aunque no exclusivamente dado que consultamos también otro tipo de documentos oficiales eclesiásticos: informes, boletines informativos, planes, proyectos, actas de las iglesias patrocinantes de la Junta Unida de Misiones, etc.). Dichas cartillas fueron traducidas al castellano por uno de los autores del artículo, David García, quien también realizó aportes sustanciales para la comprensión histórica etnográfica del contexto de difusión y uso de las mismas. De manera complementaria, recurrimos a entrevistas en profundidad realizadas por una de las autoras (2011-2017) a interlocutores clave de los procesos en estudio, tanto indígenas como no indígenas.

Para dar cuenta de los objetivos y las sintetizadas líneas temáticas de la HCE que abordan la histórica relación de los pueblos indígenas con la cultura escrita, el artículo se encuentra organizado en cuatro apartados. En primer lugar, realizamos una descripción del ámbito institucional donde fueron utilizadas las cartillas, atendiendo a la política misional, áreas de cobertura y actividades desarrolladas, los principales actores intervinientes y la población destinataria. En el siguiente apartado, reconstruimos la política y las acciones de alfabetización. Seguidamente, nos focalizamos en el análisis de las cartillas Elena qataq Elí y Lede Qom, en cuanto a sus características físicas, procesos de edición y autores, contenidos incorporados, metodologías de enseñanza, destinatarios y consideraciones lingüísticas en torno al idioma de entrada a lo escrito. Por último, presentamos conclusiones que se desprenden de la reconstrucción histórica y el análisis realizado.

${ }^{1}$ La provincia se encuentra ubicada al nordeste del país. Por su parte, a escala geográfica local, el noroeste chaqueño está integrado por las localidades de Tres Isletas, Juan José Castelli, Miraflores, Fortín Lavalle, El Espinillo, entre otras. Actualmente residen en la provincia, integrantes de las etnias qom, wichí, moqoit. 
Almirón, García y Liva. “Que el qomle’ec, el toba, no es cualquier cosa...”: la enseñanza del qom en e el ámbito...

\section{El ámbito institucional "Junta Unida de Misiones": política de un emprendimiento misional entre indígenas del noroeste chaqueño}

Misioneros protestantes arribaron en el año 1965 a Juan José Castelli (Chaco, Argentina), ${ }^{2}$ en un contexto local de necesidades, demandas y procesos de organización comunitaria indígena. Desde finales de los ' 50 , referentes indígenas del noroeste chaqueño realizaron demandas ante el Estado provincial en relación con: la entrega de tierras, herramientas, semillas y créditos para tareas agrícolas; la creación de escuelas para la infancia indígena; y la atención en salud para la cura de epidemias como la tuberculosis ${ }^{3}$ y la tos convulsa ${ }^{4}$. En el relato retrospectivo del qom Ceferino Castro, quien fuera un referente principal y pastor de la comunidad en J. J. Castelli, se describe al respecto:

"Esos tres dirigentes se fueron para Resistencia para hablar con el gobernador. Salieron a caballo pasando por diferentes lugares hasta que pudieron llegar a Castelli, a $300 \mathrm{~km}$. de Resistencia. Desde Castelli tomaron un tren que los llevaba hasta Resistencia. Cuando llegaron hablaron con el gobernador Ducca y le presentaron las necesidades de los tobas de Espinillo. El gobernador respondió satisfactoriamente al pedido de Ceferino y sus colaboradores dándoles una orden que en la delegación de Castelli que estaba a cargo del Sr. Vicente Escarano le entregarían lo acordado (...).

Pasados unos años hubo elección en Chaco...resultando ganador Felipe Bittel. Nuevamente fueron a Resistencia para hablar con el nuevo gobernador. Recibieron las mismas cosas que antes y también le dieron un carnet para trabajar en la comisaría de Fortín Lavalle en donde estaba el comisario Carlos Brandán. Su trabajo era ayudar a algún hermano toba que estuviese en problemas",

En este contexto local, a su arribo los religiosos inauguraron una misión bajo la denominación "Misiones Cristianas Evangélicas Unidas", de carácter interdenominacional con la participación de la Iglesia Evangélica Metodista Argentina, la Iglesia Discípulos de Cristo y Menonita. En el año 1966 se reemplazó la denominación MECU por Junta Unida de Misiones (en adelante JUM). ${ }^{6}$

\footnotetext{
2 De acuerdo con el informe elaborado a finales de 1960 por el equipo de antropólogos a cargo de Esther Hermitte y equipo, J. J. Castelli tenía una población estimada de 4.782 habitantes, era la localidad cabecera del Departamento General Güemes, el centro principal de servicios (contaba con dos grandes almacenes, tiendas de provisión, un hospital y médicos particulares), de la producción agrícola y de atracción de mano de obra indígena para las épocas de cosecha en la región noroeste (Hermitte et. al., 1995, Tomo II).

3 En ese periodo, por la falta de asistencia médica la tasa de mortalidad por la tuberculosis o TBC era muy alta entre la población indígena del noroeste, tanto qom como wichí (Hermitte et. al., 1995. Tomo III).

${ }^{4}$ Reivindicación. Órgano indigenista chaqueño. Octubre de 1958. Año II, $\mathrm{N}^{\circ} 131958$, p.3.

5 Ceferino Castro, en Castro y Oyanguren (2010, p.91-92).

${ }^{6}$ A lo largo de estos 64 años la JUM continuó realizando acciones entre indígenas del noreste del Chaco.
} 
El propósito de la misión era el desarrollo de acciones asistenciales y evangelizadoras destinadas a indígenas de la región noroeste: "establecer entre los tobas argentinos una misión al servicio cristiano, médico-social-educacional, en colaboración con la obra religiosa de la Iglesia Evangélica (Toba)"”. En el relato de los participantes la apertura de la misión tuvo significados diversos. Para el menonita Albert Buckwalter, que acompañó en los primeros años al desarrollo de la misión, esta representaba una nueva etapa en la evangelización indígena: "The arrival of Don Enrique [Cichetti] marks a new phase in the evangelical work among the Tobas. Not only will he treat sick bodies, but he is an evangelical Christian. Never before have the Tobas met a doctor who was also

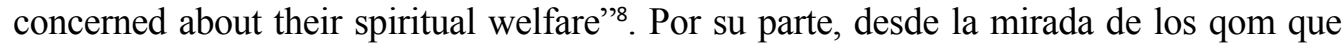
participaron de la JUM, actualmente pastores y/o docentes bilingües interculturales, la intervención de los protestantes constituyó un hito muy presente y valorado positivamente en la actualidad. En la construcción simbólica, dicha intervención se asoció a la difusión del evangelio y al acceso a bienes sociales y culturales:

"Pero la JUM hizo... son los gestores de los momentos más difíciles de los Qom, el tema de documentación, el tema de salud, el tema educación... Si no hubiese sido la JUM no sé si en esta tierra estaría viviendo la Qom... la JUM cultivó un montón de cosas, el derecho a tener una casa, a tener un hogar"'. “...ellos trajeron viste...todo... salud por ejemplo, el trabajo, el camino, y hasta ahora por eso la gente siempre se acuerda de Cicchetti. Como si fuera un hermano propio. Hermano viste por....por el evangelio digamos" 10 .

Con cambios en las orientaciones de la política misional, en la actualidad la institución está enfocada en actividades en torno a la educación y la promoción de los derechos de los Pueblos Indígenas. En educación una de las acciones más destacadas fue la creación del Centro Educativo El Colchón (CEREC) en 1987, institución de carácter bilingüe e intercultural. En 1999 obtuvieron la personería jurídica como Federación Junta Unida de Misiones.

Para ampliar sobre las tareas desarrolladas: http://federacionjum.org.ar/quienes-somos/

7 Iglesia Metodista. Actas Oficiales de la Septuagésima Quinta Reunión de la Conferencia Anual en la Argentina. (1967). Acta de Constitución de la Junta Unida de Misiones.

8 Buckwalter, A. (20 de marzo de 1965). El Chaco Argentino.

En castellano: "La llegada de Don Enrique [Cichetti] marca una nueva fase en el trabajo evangélico entre los Tobas. No solo atenderá él cuerpos enfermos, sino que él es también un Cristiano evangélico. Nunca antes los Tobas conocieron a un doctor que estuviera además preocupado por su bienestar espiritual". Traducción realizada por Jesús Lenain del Departamento de Lenguas Extranjeras, Facultad de Humanidades, UNNE.

9 Entrevista a Cornelio Romero, diciembre de 2017. El entrevistado es qom, Oriundo de El Espinillo (Chaco), actualmente radicado en Juan J. Castelli. Pastor evangélico con 39 años de antigüedad. Se formó en la ciudad de Pcia. Roque Sáenz Peña en el Seminario Bíblico de Fe (1986) y en el anexo del ISEDET instalado en el barrio Nocaayi' (Juan J. Castelli). Trabajó en la traducción de la biblia, y además del pastorado se dedicó a la enseñanza del estudio bíblico en muchas iglesias de la provincia.

${ }^{10}$ Entrevista a Cornelio Castro, marzo de 2015. El entrevistado es qom, es hijo de Ceferino Castro renombrado pastor y referente qom que estuvo a cargo de la IEU durante el periodo en estudio. Nació en la zona de El Espinillo (Chaco), actualmente radicado en Juan J. Castelli. Es pastor, uno de los revisores de la Biblia, enseña qom en una escuela de modalidad EBI, y realiza textos escritos sobre la lengua e 
Almirón, García y Liva. “Que el qomle’ec, el toba, no es cualquier cosa...”: la enseñanza del qom en e el ámbito...

"Porque, te imaginas, cuántos años han pasado, esa clase [en la escuela de la JUM] fue como si lo estuve participando ayer, la semana pasada, muy importante, uno no se olvida... Yo me acuerdo de algunas felicitaciones, y no entendía por qué me felicitaba. Eso me hizo muy bien, me hizo ver que la escuela es importante, me hizo crear en la mente que la educación es muy importante" $" 11$ (la aclaración es nuestra).

Cuando arribaron a la ciudad, integraban la JUM los misioneros metodistas: Humberto Enrique Cicchetti, médico argentino, y su esposa norteamericana Virginia Bunn -quienes provenían de una experiencia misional con indígenas aymara de Bolivia-y las enfermeras Elizabeth Stauffer, de Suiza, y Ruth Clark de Estados Unidos respectivamente. Posteriormente, participaron otros misioneros de los cuales destacamos las figuras de la maestra Ruth Woods y de Carlos Benedetto, quienes se desempeñaron como alfabetizadores.

Imagen 1. Misioneros/as e indígenas asistentes a la JUM, s/f.

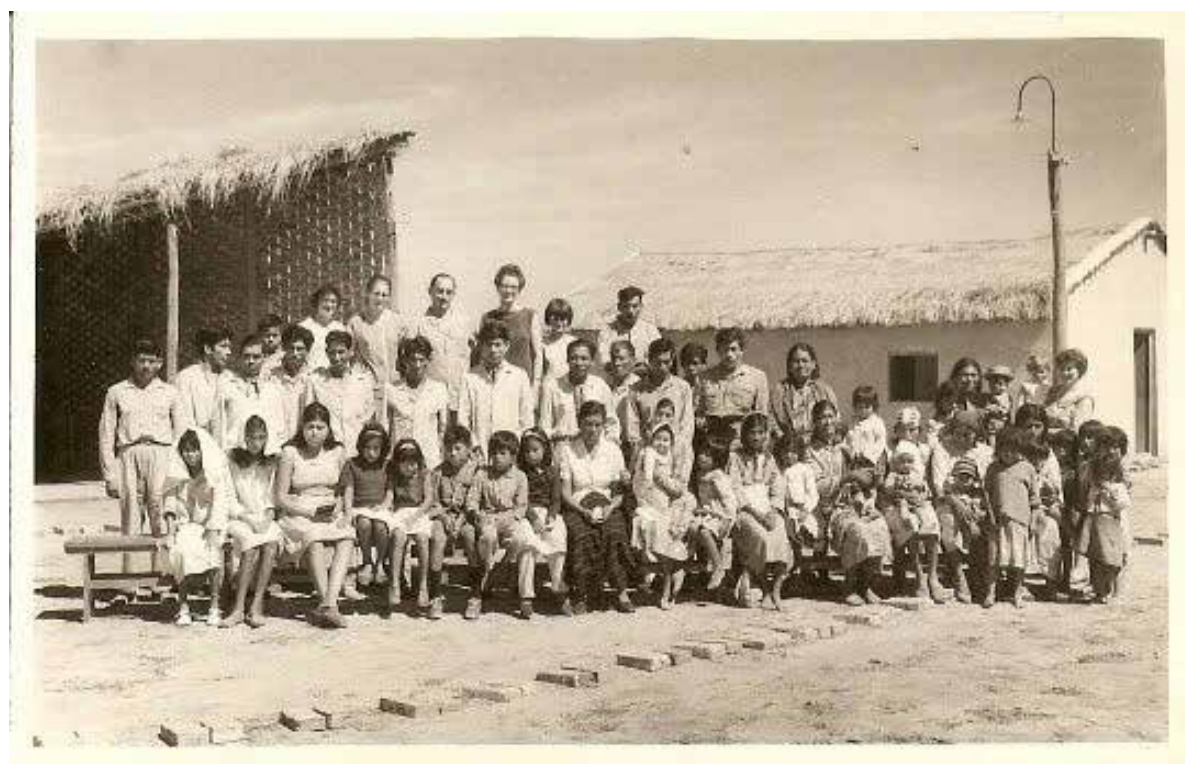

Fuente: Archivo personal de Wanda Cicchetti.

Desde 1967 indígenas qom se incorporaron paulatinamente a las tareas: José Romero, Josefina López, Genaro Sotagag, Rubén Rodríguez, Mario Charole y Beatriz Inderecio. Relativo a la incorporación, informantes clave y fuentes documentales refirieren:

historia qom.

${ }^{11}$ Entrevista a José Celín, marzo de 2015. El entrevistado es qom, oriundo de la zona de la Confluencia del Teuco Bermejito (Chaco). Auxiliar docente aborigen egresado del Centro de Investigación y Formación para la Modalidad Aborigen de la ciudad de Pcia. Roque Sáenz Peña. Actualmente vive en Juan J. Castelli y trabaja en escuelas de modalidad bilingüe intercultural. 
"En Pampa Argentina a 15 km. Donde la misión levantó una enfermería atendida por un aborigen capacitado para dar inyecciones"12.

"[Virginia] Nos hizo alumnos de ella, hasta lo último nos preguntó si animar a enseñar a los chicos a leer. Y le dije que sí, sí. Con José Romero finado. José Romero tiene experiencia de leer. Bueno, estuvimos ahí. Enseñando a los chicos. Varios años estuvimos ahí, hasta que llego la zafra de cosecha cañera y dejé la escuela y me fui para allá"13 (la aclaración es nuestra). "Había enfermeros indígenas también, veía que tenían una formación, eran bastante formados. Sabían atender a la gente, tenían una manera de atender a la gente. Eran personales institucionales muy bien formados" ${ }^{\text {. }}$.

"No sé si Virginia escribió muy bien el idioma, porque el que más promovió todo era la mano derecha de Virginia, es José Romero, porque vivía en la casa del doctor Cicchetti. Genaro Sotagag, Beatriz Inderecio, que fueron alumnos de ella, seguramente siempre había reuniones para corregir todo la forma como es escribir"'15.

En el primer año las acciones de la JUM se enfocaron en el área religiosa, la salud y educación. Entre 1966-1970 ampliaron progresivamente las áreas en cuanto a actividades, lugares de cobertura, infraestructura y equipamiento. A partir de 1966 se abrieron puestos sanitarios en otros parajes rurales o pueblos: Miraflores, Pampa Argentina y Pozo Toro ${ }^{16}$. El primero fue abierto por solicitud de indígenas, llegando a contar con una enfermera permanente. En Pampa funcionó contiguo al edificio de una iglesia evangélica dirigida por indígenas. En el último, Pozo Toro, se atendía también en el edificio eclesiástico o desde el vehículo particular de la JUM. Las visitas a estos anexos eran semanales.

El carácter integral de la misión y su ritmo de trabajo exigían a los misioneros una dedicación permanente: "La tarea es inmensa, inacabable y la necesidad pavorosa"17. El relato del qom Cornelio Romero, nos acerca etnográficamente a las actividades, los tiempos, los participantes, la reciprocidad entre las distintas tareas que se desarrollaban:

“(...) son intensas [las actividades], Virginia está abocada a la enseñanza pero también está abocada con el tema de la música.

${ }^{12}$ Ortega, H. (1966). Operación Toba.

${ }^{13}$ Entrevista a Genaro Sotagag, diciembre de 2017. El entrevistado es qom, nacido en El Espinillo (Chaco). Se trasladó a Juan J. Castelli con sus padres y hermanos al crearse la JUM. Es miembro de la IEU de Juan J. Castelli, al momento de la entrevista tenía el cargo de revisor de cuentas.

${ }^{14}$ Entrevista a José Celín, marzo de 2015.

${ }^{15}$ Entrevista a Cornelio Romero, diciembre de 2017.

${ }^{16}$ Consejo de Misiones y Avance. Septiembre de 1968. Situación de la obra misionera entre los Tobas. Junta Unida de Misiones.

${ }^{17}$ Consejo de Misiones y Avance. (Agosto de 1965). Carta a los pastores de las Iglesias Metodistas de Argentina. 
Almirón, García y Liva. “Que el qomle’ec, el toba, no es cualquier cosa...”: la enseñanza del qom en e el ámbito...

Los sábados hay campeonato, hay futbol, una multitud, pero después de ahí también está la iglesia, hay grupos de ancianos. Están los enfermos, de ahí los llevaban a la iglesia"18 (la aclaración es nuestra).

Debido a la envergadura que fueron adquiriendo las tareas misionales en $\mathrm{J}$. J. Castelli, la extensión a otros parajes fue disminuyendo y hacia finales de los ' 60 las acciones se concentraron en dicha localidad. Con la ejecución de un proyecto de desarrollo económico, en 1972 se expandió la cobertura en la zona del Interfluvio Teuco Bermejito, actualmente conocido como El Colchón. La misión estaba destinada principalmente a la población qom, que provenía de parajes rurales o localidades aledañas a J. J. Castelli. Con la expansión misional y ampliación de las acciones, posteriormente comenzaron a asistir a indígenas de otras regiones del Chaco: Cabá Ñaro, Las Palmas y Colonia Aborigen Chaco. Debido a la escasa atención sanitaria, recibieron también a población wichí de la zona conocida como El Impenetrable ${ }^{19}$. Eran asistidos, también los lugareños no indígenas a quienes cobraban un aporte destinado al mantenimiento de la JUM, a diferencia de los indígenas que recibían atención gratuita.

Entre sus acciones principales, la JUM estableció una "clínica"20 para paliar el estado sanitario crítico de la población indígena a causa de la tuberculosis (TBC). Habiéndose incorporado Cicchetti como médico al hospital de la ciudad, también atendía a indígenas en el nosocomio, podía tomar radiografías, internar y entregar medicamentos suministrados por el Estado provincial ${ }^{21}$. En el año 1967 comenzó la edificación de un albergue para la internación de pacientes con TBC, inaugurado finalmente en enero de 1968 como "Monte Alto", con una capacidad para 20 personas, bajo el lema "techo y lecho". Desde la JUM se cubrían los insumos médicos, los medicamentos y la manutención diaria para las personas internadas y familiares, las otras demandas sanitarias ambulatorias continuaron siendo asistidas en la clínica o en el hospital estatal.

\footnotetext{
${ }^{18}$ Entrevista a Cornelio Romero, diciembre de 2017.

${ }^{19}$ Con la llegada de un grupo de católicos tercermundistas los wichí de la zona comenzaron a recibir asistencia en Nueva Pompeya, y la JUM era un centro de atención para pacientes graves. Como lo registraron Hermitte et. al. (1995) "Cuando se presentan casos graves son mandados a Castelli (200 km) por avioneta (...). Los enfermos llevados a Castelli, sobre todo indígenas, son atendidos en el hospital del Doctor Cicchetti, dirigente evangelista y médico, donde los indios son muy bien tratados. En algunos casos, quedan allí internados" (1995. Tomo II: 95)

${ }^{20}$ Término usado en las fuentes, en el sentido de atención privada y distintivo al hospital público estatal.

${ }^{21}$ En 1965 aprobaron en la Iglesia Metodista ayuda financiera para crear en el hospital público una sala de atención a indígenas con TBC. (Consejo de Misiones y Avance, agosto de 1965; Carta a los pastores de las Iglesias Metodistas de Argentina).
} 
Imagen 2. Albergue Monte Alto. Juan J. Castelli, s/f.

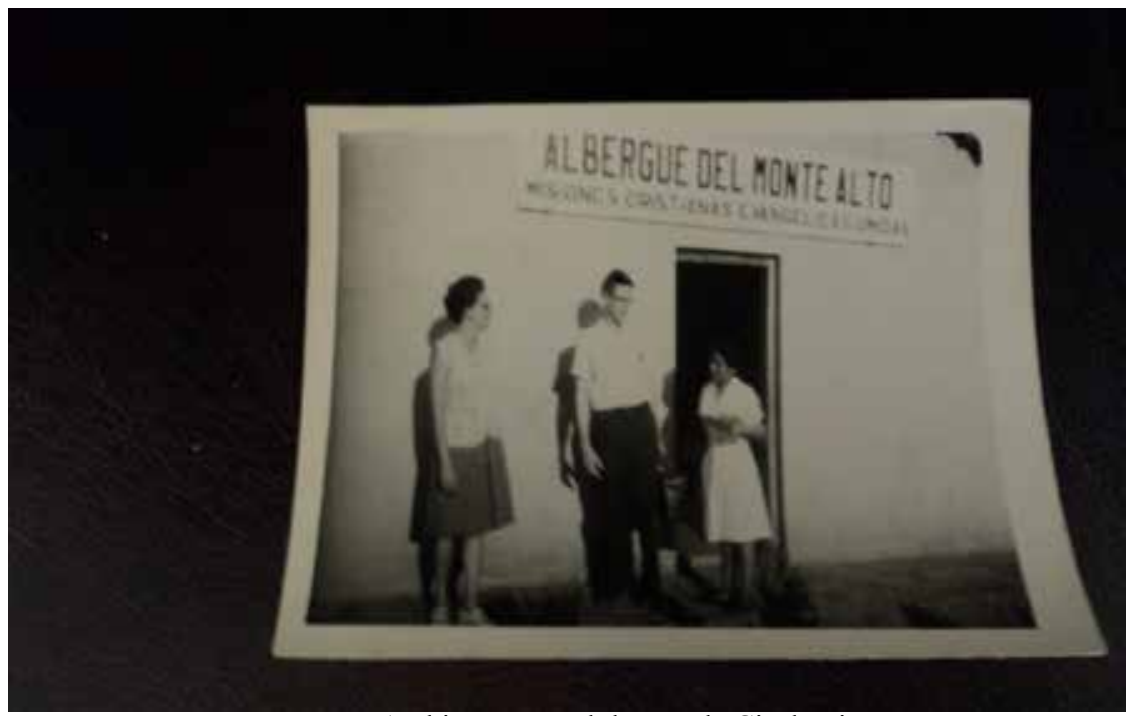

Fuente: Archivo personal de Wanda Cicchetti.

Por otro lado, la obra religiosa fue una parte constitutiva importante de las actividades de la JUM. El propósito de la misión era acompañar a la expansión de la Iglesia Evangélica Unida (en adelante IEU) y la formación de líderes religiosos indígenas que difundían el evangelio entre Chaco y Formosa. El grupo de misioneras/os no indígenas participaban en las celebraciones, liturgias y rituales religiosos de la IEU, cumpliendo funciones clave para la formación teológica y la exegesis bíblica, como por ejemplo la prédica:

"La obra espiritual: nuestros obreros no fueron allí a abrir una iglesia, que ya existe y es la Iglesia Evangélica Unida, 100\% toba. Ellos trabajan dentro de esta iglesia participando en sus cultos, predicando, compartiendo momentos de confraternidad cristiana, edificándoles en el conocimiento de la Biblia. Se calcula que de los 22.000 existentes el $90 \%$ son evangélicos, reunidos en 48 congregaciones" 22 .

En el relato de los indígenas entrevistados, por la implicación del grupo misional de la JUM en las actividades de la IEU en su periodo fundacional, Cicchetti es visto como el fundador de la iglesia y una figura de autoridad espiritual en J. J. Castelli y parajes aledaños:

"Era como un padre en la iglesia, todos los domingos termina el culto y se queda con la gente"23;

"Viste por...por medio de ese hombre Cicchetti que dio a la

\footnotetext{
${ }^{22}$ Ortega, H. (1966). Operación Toba. Colección Obispo Sante Uberti Barbieri.

${ }^{23}$ Entrevista a Cornelio Romero, diciembre de 2017.
} 
Almirón, García y Liva. “Que el qomle’ec, el toba, no es cualquier cosa...”: la enseñanza del qom en e el ámbito...

gente, la primera escuela y la iglesia. Cicchetti tiene un carrito de... zulqui y un caballo para ir a la iglesia. A veces sale una legua, dos leguas de acá en el campo cuando hacen bautismo. La cultura toba se van caminando, cantando y Cicchetti está en el medio de los Qom"24.

Imagen 3. Culto religioso. En el centro Cicchetti con un libro en la mano, s/f.

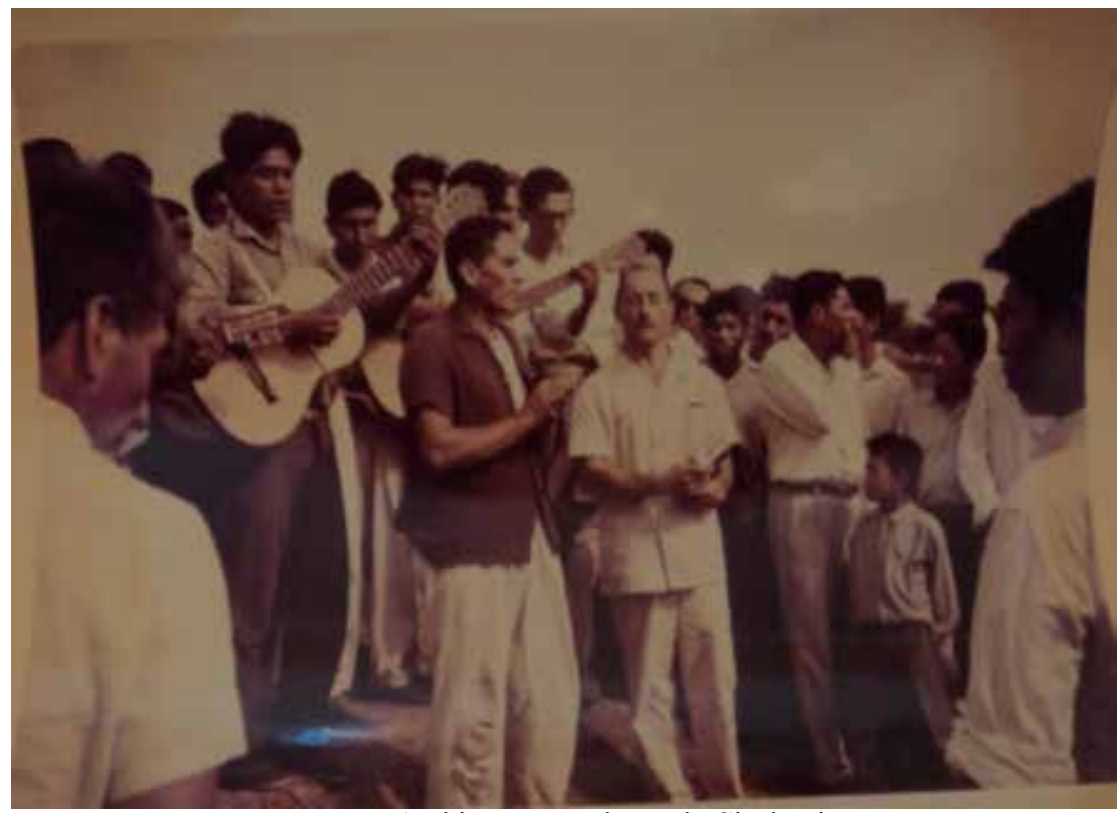

Fuente: Archivo personal Wanda Cicchetti.

Entre otras acciones desempeñadas por la JUM valdría mencionar que fue creado el primer barrio indígena en J. J. Castelli, "Nocaayí", por solicitud de la comunidad que residía en la zona aledaña al albergue. Asimismo, desde 1969 comenzó la proyección de actividades económicas, en concurrencia con las políticas indigenistas del periodo y la articulación con el Estado, centradas en la agricultura, la explotación forestal y el desarrollo artesanal.

\section{El espacio educativo de la JUM: sentidos y orientaciones de la política de alfabetización}

En la JUM, las primeras acciones desarrolladas en el ámbito educativo fueron prácticas de alfabetización en J. J. Castelli25. Primero bajo un árbol de algarrobo

${ }^{24}$ Entrevista a Cornelio Castro, marzo de 2015.

${ }^{25}$ Cuando iban a otros parajes rurales para la atención sanitaria también se alfabetizaba a la población, aunque estas prácticas no eran tan sistemáticas como en el caso de Juan J. Castelli (Consejo de Misiones y Avance, 12 Julio de 1966; Informe a la Junta General). 
y, a partir de 1968, edificaron una escuela en el Albergue Monte Alto y obtuvieron reconocimiento oficial ${ }^{26}$. En 1972 la escuela fue trasladada al barrio Nocaayi' y la denominaron "Sayaten" (en castellano "Yo lo sé"). Con el programa de Promoción Rural Comunitaria "Chaco", desde 1973 extendieron la alfabetización entre las familias qom residentes de la zona del Interfluvio Teuco Bermejito.

Las prácticas de alfabetización estaban dirigidas a los qom, mujeres y hombres; a diferencia de la atención sanitaria no se encontraron registros de la participación de wichí y de no indígenas. Durante los primeros años se alfabetizaba a la infancia, pero esta intervención fue ampliada posteriormente a todas las edades. Las familias que recibían atención sanitaria eran quienes, además, participaban de la alfabetización. Los principales alfabetizadores no indígenas fueron Virginia Bunn, Ruth Woods y Carlos Benedetto. Temporalmente, también trabajó en la tarea la maestra Olga Vossler, quien fue la única alfabetizadora que no era misionera y su incorporación estuvo vinculada al Programa Nacional Intensivo de Alfabetización. En una entrevista realizada a Vossler, la alfabetizadora señaló la discriminación que sufrían los indígenas, refiriendo que fue convocada "porque nadie quería trabajar allí con los indígenas" ${ }^{27}$. Como hemos señalado, desde 1968 algunos qom se integraron paulatinamente a las actividades de la JUM, como alfabetizadores se desempeñaron José Romero, Genaro Sotagag y Beatriz Inderecio.

Dentro del proyecto misional fueron diversas las finalidades otorgadas a la alfabetización: religiosa, integracionista y/o para la "liberación". Siendo una obra de carácter misional, representó un instrumento privilegiado para la difusión del evangelio a través de la lectura bíblica. En cuanto a la política integracionista, también tenía por finalidad integrar a la sociedad nacional, en concurrencia con el Estado a través de campañas de alfabetización: “(...) la integración del toba a la sociedad nacional no puede darse como un hecho aislado sino como factor correlativo e integral a los de su salud y educación"28. Por otra parte, fuertemente influenciado con el viraje en la política nacional, hacia 1973 la ejecución de la Campaña de Reactivación Educativa del Adulto para la Reconstrucción (CREAR) y la adhesión de sectores del protestantismo a la teología de la liberación, la alfabetización en el Interfluvio del Teuco Bermejito tenía el propósito de acompañar un proceso de emancipación, en clave de liberación de sectores populares.

Asimismo, en la JUM alfabetizaban para el aprendizaje simultáneo de la lectura y la escritura, y de los idiomas qom y castellano. Estas prácticas se fueron difundiendo paulatinamente entre los diferentes grupos etarios y en un ámbito comunitario de socialización intercultural. En ese sentido, en términos lingüísticos la JUM desenvolvió

${ }^{26}$ Ortega, H. (septiembre de 1968). Carta a los pastores, juntas oficiales y miembros de la Iglesia Metodista en Argentina.

${ }^{27}$ Entrevista a Olga Vossler, marzo 2017. La entrevistada es oriunda de la ciudad de Juan J. Castelli (Chaco), maestra egresada de la escuela normal. Luego de su paso por la JUM, emigró a España junto a su familia donde actualmente reside.

${ }^{28}$ Palaci, Elsa y Peiró, Ángel (enero de 1968). Recomendaciones de la consulta sobre la obra misionera entre los Tobas. 
Almirón, García y Liva. “Que el qomle’ec, el toba, no es cualquier cosa...”: la enseñanza del qom en e el ámbito...

una propuesta de alfabetización bilingüe. Vale destacar que, en el contexto discursivo de la época, a nivel local como regional latinoamericano, surgió como un tópico de interés el uso de la lengua nativa en los espacios de enseñanza, así como el aprendizaje de los idiomas nacionales. Tal es el caso de la UNESCO que, fundamentada en principios de no discriminación y derecho universal a la educación, establecía:

1. Los Estados Partes en la presente Convención convienen:

c. En que debe reconocerse a los miembros de las minorías nacionales el derecho a ejercer las actividades docentes que les sean propias, entre ellas la de establecer y mantener escuelas $\mathrm{y}$, según la política de cada Estado en materia de educación, emplear y enseñar su propio idioma, siempre y cuando:

(i) Ese derecho no se ejerza de manera que impida a los miembros de las minorías comprender la cultura y el idioma del conjunto de la colectividad y tomar parte en sus actividades, ni que comprometa la soberanía nacional (UNESCO, 1960, art.5)

Desde la perspectiva del grupo misionero, se entendía al uso del idioma nativo como una condición imprescindible para realizar el proyecto evangelizador ${ }^{29}$ : “(...) aprender el idioma y leer en el idioma les permitía leer las escrituras, las sagradas escrituras en el idioma, que se habían empezado a traducir a través de un misionero menonita"30.

A la vez, en la interrelación con procesos de construcción de la aboriginalidad, para el grupo misionero alfabetizar en qom contribuía a sostener una política integracionista y las relaciones interculturales en base a la puesta en valor de las pautas culturales indígenas: “(...) por lo cual recomiéndase llevar a cabo una labor integral, a la vez que respetando las pautas de existencia y valores que hacen a la vida toba" ${ }^{31}$. Tenía el propósito de favorecer la valorización del diacrítico identitario, y desde allí sostener el aprendizaje posterior del castellano y la escolarización. El alfabetizador Benedetto explica que en la JUM importaba que los qom aprendieran a leer y a escribir en su propio idioma, para "que dominen su propia lengua y una vez que dominan su lengua que vayan a la escuela pública común"’32. Otras fuentes refieren:

“... porque hay que enseñarles a escribir el toba. Sí, el toba.

Ellos deben comenzar por valorar la palabra escrita y luego

\footnotetext{
${ }^{29}$ La continuidad histórica de esta práctica con los orígenes del protestantismo y la difusión de la alfabetización para la lectura directa de la Biblia en lenguas vernáculas (Gilmont, 1998; Chartier, 1999; Lyons, 2012).

${ }^{30}$ Entrevista a Carlos Benedetto, septiembre de 2011. El entrevistado es oriundo de la provincia de Buenos Aires. Misionero protestante, participó en la JUM desde sus primeros años de desarrollo. Fue alfabetizador, profesor de matemáticas y cumplió funciones como Director de la Dirección del Aborigen en la década del '80. Bajo su dirección, fue sancionada en 1987 la Ley $\mathrm{N}^{\circ} 3258$ y creado el primer organismo indígena autárquico, el Instituto de Aborigen Chaqueño (IDACH).

${ }^{31}$ Palaci, Elsa y Peiró, Ángel (enero de 1968). Recomendaciones de la consulta sobre la obra misionera entre los Tobas. Colección Obispo Sante Uberti Barbieri.

${ }^{32}$ Entrevista a Carlos Benedetto, septiembre de 2011.
} 
poco a poco ir introduciéndolos al castellano"33.

"Pero el problema de alfabetización es más complejo de lo que parece. Es necesario que el aborigen aprenda a escribir en su propio idioma. El toba, idioma de sonidos cortantes y guturales, es un idioma sin escritura. El reverendo Albert Buckwalter, pastor-antropólogo de la iglesia menonita, le ha puesto la escritura al toba y con la base de este trabajo Virginia ha elaborado varias cartillas graduadas donde los aborígenes comienzan a descubrir el valor del idioma escrito. Recién después se les puede enseñar el castellano" ${ }^{34}$.

De acuerdo con los datos que aporta la última fuente, Operación Toba (1966), y otras consultadas, para la alfabetización en el idioma nativo existió una estrecha colaboración del menonita Albert Buckwalter. Enseñó el qom a Virginia Bunn y Carlos Benedetto, asistía en la elaboración de cartillas, y proveía de textos que se utilizaban para la enseñanza, como traducciones de la Biblia y vocabularios. Asimismo, el empleo de las traducciones en la alfabetización por parte de los misioneros de la JUM, servía a Buckwalter para difundir y evaluar cómo era recibido el trabajo de escritura del qom, que venía realizando desde mediados de los '50, entre las parcialidades del noroeste chaqueño ${ }^{35}$.

Por otra parte, la significación otorgada por las y los participantes qom de la alfabetización en lengua indígena fue disímil para Beatriz Inderecio, Cornelio Romero, José Celín y Cornelio Castro. Beatriz Inderecio recordaba que poder hablar en su idioma, en la escuela de la JUM, marcó una diferencia profunda con respecto a la escuela pública donde asistió posteriormente, ya que allí estaba prohibido y era sancionada si la encontraban hablando en la lengua materna ${ }^{36}$. Por su parte, Cornelio Romero estaba en desacuerdo con que lo alfabetizaran en qom: "Nunca estaba de acuerdo con aprender mi idioma, escribir, porque no me gustaba, parece una ofensa. Pero al correr el tiempo ahora uno recién entiende y descubre el valor de nuestro propio idioma"37.

Desde una significación contrapuesta, Cornelio Castro sostuvo que para él fue significativo alfabetizarse en qom, por el sentido religioso y evangelístico de los textos: "Muy lindo es para mí, leo en toba parece que me alienta, más ánimo, más fe" ${ }^{38}$. Finalmente, el testimonio de José Celín aporta elementos para aproximarnos a los alcances de la alfabetización en lengua indígena en el ámbito familiar:

Mi papá siempre tenía la idea de que el castellano es algo fundamental, es eso lo que tenés que aprenderlo. Mi mamá

\footnotetext{
${ }^{33}$ S/a. (octubre de 1966). El Estandarte Evangélico. p. 108.

${ }^{34}$ Ortega, H. (1966). Operación Toba.

${ }^{35}$ Entrevista a Mabel Dalmas y Jorge Collet, septiembre de 2011. Misioneros protestantes no indígenas quienes actualmente se encuentran a cargo de la JUM.

${ }^{36}$ Entrevista a Beatriz Inderecio, diciembre de 2015. La entrevistada es qom, es oriunda de El Colchón (Chaco). Actualmente se desempeña como auxiliar docente aborigen en la zona de El Bermejito (Chaco).

${ }^{37}$ Entrevista a Cornelio Romero, diciembre de 2017.

${ }^{38}$ Entrevista a Cornelio Castro, marzo de 2015.
} 
Almirón, García y Liva. “Que el qomle’ec, el toba, no es cualquier cosa...”: la enseñanza del qom en e el ámbito...

me decía que no, que es muy bueno que el alumno indígena aprende primero su lengua y después el español. Porque los dos son importantes. Porque ella dice si cuando tenés que explicarle algo a un chico lo tenés que hacer en su lengua, no le podes explicar en español"39.

Estas múltiples significaciones nos permiten pensar en las posturas heterogéneas que los indígenas adoptaban respecto de la política de alfabetización bilingüe, el sentido que le otorgaban a los idiomas en relación con la transmisión intergeneracional y los intercambios con la sociedad envolvente, donde incluso en una misma familia ambos progenitores podían tener posiciones contrapuestas.

\section{Imagen 4. Virginia Bunn y Olga Vossler en la escuela del albergue del Monte Alto, 1968}

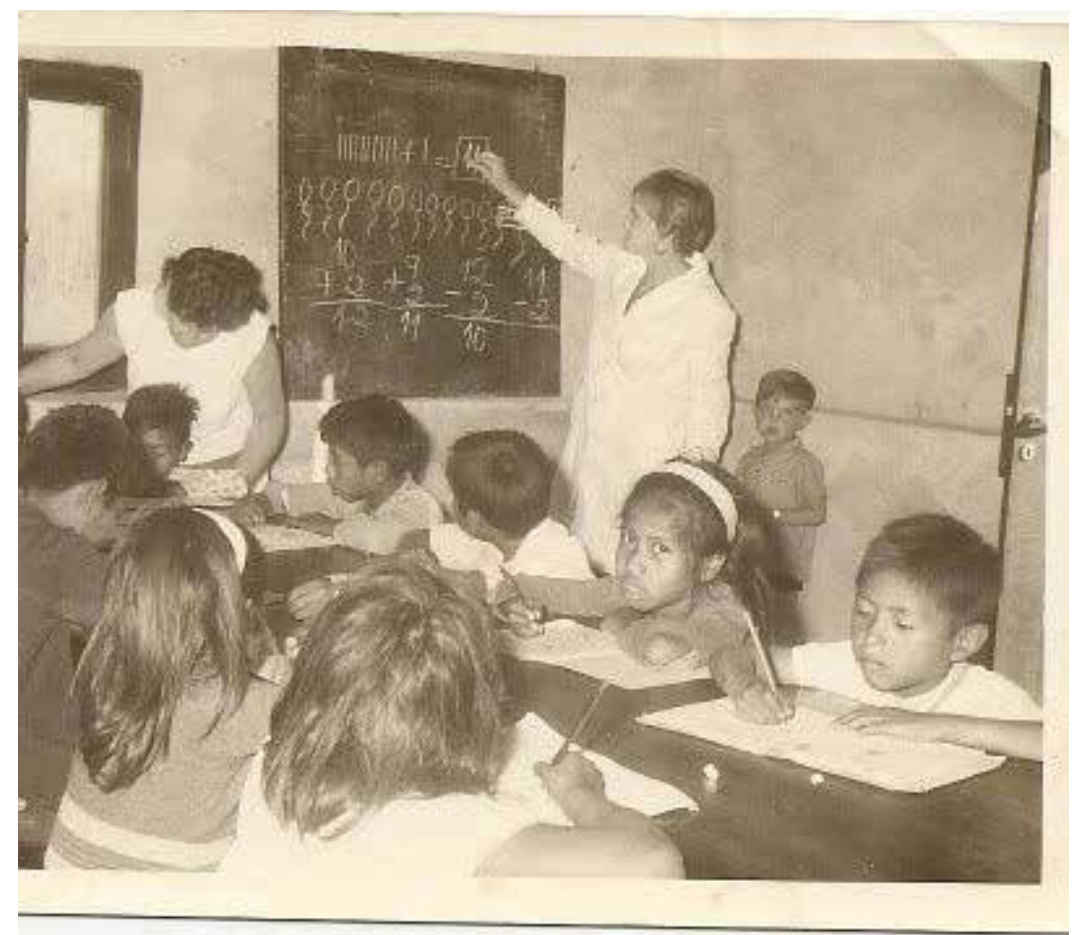

Fuente: Archivo personal de Olga Vossler.

\section{Textos de enseñanza para la alfabetización en qom}

En la introducción expusimos los aportes del análisis de los materiales de lectura a los estudios que abordan la historia de la cultura escrita. Como anticipamos, estos evidencian la norma oficial, el canon literario, los modelos de leer y las maneras de escribir (Chartier, 2005; Petrucci, 2002). A continuación, presentamos una

\footnotetext{
${ }^{39}$ Entrevista a José Celín, marzo de 2015.
} 
descripción de los materiales de lectura utilizados en los espacios de alfabetización en la JUM, teniendo en cuenta el entorno más general de su uso que hemos descripto en los apartados precedentes. Con el marcado propósito de propiciar el aprendizaje simultaneo del qom y el castellano, los textos que circularon en la JUM eran bilingües, o exclusivamente qom. Se presentaban en distintos géneros y, según su contenido, eran de tipo educativo, literario, lingüístico o religioso: cartillas de alfabetización, periódico escolar y láminas, series de cuentos clásicos (Alí Babá y los 40 ladrones, El Flautista de Hamelín), glosarios de palabras en qom, fragmentos de la Biblia en qom (libros, capítulos, versículos o historias bíblicas $)^{40}$.

Para la confección de textos bilingües o monolingües en qom, se recurrió a la participación de indígenas letrados y la colaboración de Buckwalter. Las cartillas de alfabetización fueron elaboradas por la alfabetizadora Virginia Bunn, con el asesoramiento lingüístico de Albert Buckwalter y, en algunas de ellas, en colaboración con el indígena José Romero y en consulta con ancianos qom para la selección de contenidos. Desde el año 1966 encontramos registros de su elaboración: "Virginia trabaja en la alfabetización, junto con Buckwalter preparó una serie de cartillas y confeccionó un curso para hacer del qom un idioma escrito paso previo a la enseñanza del castellano" ${ }^{41}$. Por su parte, los cuentos clásicos fueron traducidos al qom por el indígena Francisco Rodríguez, quien había iniciado con Buckwalter el proceso de escritura del qom.

Las cartillas de alfabetización, partes de la Biblia y glosarios fueron utilizados en los dos ámbitos educativos referidos: en J. J. Castelli (en el albergue Monte Alto y en el barrio Nocaayi') y en la zona de influencia Teuco Bermejito. Las cartillas y los glosarios fueron textos centrales en la enseñanza de la lectura y escritura, y de los idiomas. En el caso de la Biblia era un material de uso para las prácticas de lectura. Virginia Bunn contaba con un mimeógrafo para reproducir los materiales; para el caso de reproducciones a gran escala, por ej. 500 copias de una de las cartillas, el material fue enviado a una imprenta de la IEMA $^{42}$. No hemos hallado registro del uso del mimeógrafo por parte de los indígenas; sin embargo, la participación en los procesos de elaboración de los textos permite conjeturar una apropiación de la cultura impresa durante los procesos de edición.

A continuación, presentamos un análisis de las cartillas Elena qataq Eli (Elena y Eli) y Lede Qom (Escritos de los Qom), las cuales tuvieron una amplia difusión y uso en el ámbito educativo de la JUM. La primera estaba dedicada a la infancia indígena, la segunda para adultos/as. En los dos materiales se observa el uso de imágenes y de textos escritos en qom; en el caso de la cartilla para la infancia se incluye una traducción completa al castellano al final. En cuanto a las imágenes, se observan figuras de animales, plantas, personas (niños, adultos o un/a anciana/o qom), objetos (libro, sombrero, aguja

\footnotetext{
${ }^{40}$ Los textos bíblicos estaban en proceso de traducción a partir del trabajo lingüístico del menonita Buckwalter y el qom Orlando Sánchez. El tiempo que llevó el proceso de traducción de libros de la Biblia al qom nos sugiere que también se podrían haber empleado versiones en castellano.

${ }^{41}$ Consejo de Misiones y Avance. (12 Julio de 1966). Informe a la Junta General.

${ }^{42}$ Los fondos fueron obtenidos de una iglesia metodista de EEUU y del obispo Sante Barbieri (Consejo de Misiones y Avance. Septiembre de 1968. Situación de la obra misionera entre los Tobas. Junta Unida de Misiones).
} 
Almirón, García y Liva. “Que el qomle’ec, el toba, no es cualquier cosa...”: la enseñanza del qom en e el ámbito...

con hilo) o situaciones que describen acciones o acontecimientos (una niña que juega, un adulto que tuvo un sueño, una anciana qom tomando mate). Tanto en las cartillas, como en las entrevistas aplicadas a indígenas participantes, hay referencias recurrentes al uso de palabras cotidianas y del lenguaje local de los qom ${ }^{43}$.

La función otorgada a la imagen está relacionada con lo expuesto por Linares (2009), acerca de reemplazar al objeto ausente en las situaciones de enseñanza, especificidad que adquirió el texto de lectura escolar en las décadas previas a los ' 60 . En el contexto lingüístico heterogéneo en el que se desarrollaba la alfabetización en la JUM, además cumplía la función de representar lo que el lenguaje no podía comunicar. De manera aproximativa, podemos mencionar que en los espacios de enseñanza los participantes podrían ser monolingües (qom) o bilingües (qom y castellano). La alfabetizadora principal, Virginia Bunn, además era anglófona con poco manejo del castellano y nulo conocimiento del qom al momento de llegar a la Misión. Por parte de las y los alfabetizadores, el aprendizaje del qom fue progresivo y en simultáneo al proceso de participación en la JUM. El misionero Buckwalter cumplió un rol destacado en este proceso de apropiación del qom (oral y escrito) por parte de las y los educadoras/es.

En las cartillas, la metodología de enseñanza era la palabra generadora. El texto escrito comenzaba con palabras -resaltando alguna vocal-, luego se presentaban oraciones cortas y finalmente textos ampliados. Los datos de autoría y edición no fueron consignados en ambas cartillas. La fecha señalada en la cartilla Elena qataq Eli, agosto de 1976, es un agregado manuscrito posterior cuya procedencia no se pudo identificar durante la investigación. Otras fuentes permitieron reconstruir el proceso de producción de las cartillas e identificar las/los autores mencionados con anterioridad como participantes de ambas producciones, pero sin mayores detalles.

\section{Elena qataq Eli: La infancia qom que lee en su propio idioma}

La cartilla consiste en un cuadernillo de tapa blanda engrampada en el medio. Es un texto impreso, contiene once páginas, cada una con párrafos cortos conformado por no más de seis oraciones breves que apelan al método del juego de palabras. Las dos últimas páginas tienen la traducción en castellano de los textos escritos en qom (en las nueve páginas anteriores). Esta disposición del texto escrito sugiere que fueron utilizadas para la lectura rápida, la circulación entre no hablantes del qom y/o el uso de alfabetizadores con limitada competencia del idioma nativo. En todas las páginas aparecen recuadros donde se resalta la letra o sílaba a trabajar. El único tipo de letra que aparece es la imprenta, en minúscula o mayúscula. Se utilizan además signos de puntuación.

La cartilla presenta como personajes principales a Elena y Eli, las lecturas contienen relatos de situaciones vividas por los dos niños junto a dos animales: un loro y un burro. Solo en una de las escenas aparece un adulto junto a la niña Elena. Las imágenes retratan el medio rural, próximo al entorno de los niños qom y de la geografía

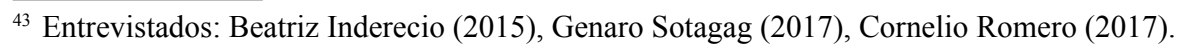


de J. J. Castelli de ese periodo: campos, árboles, la siembra de planta de maíz, el rancho con techo de paja, el uso del sombrero de paja.

Imagen 5. Cartilla de alfabetización Elena qataq Elí

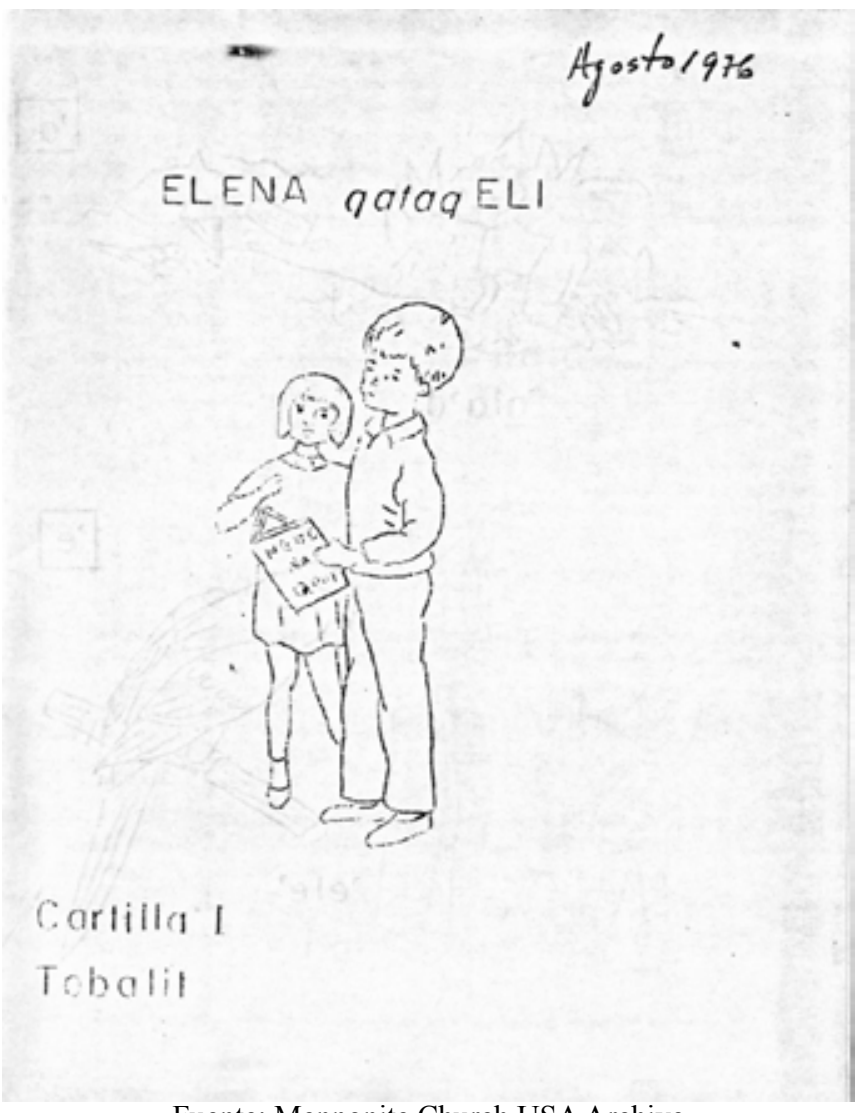

Fuente: Mennonite Church USA Archive

La portada de la cartilla representa una escena de lectura protagonizada por los dos niños y nos sugiere el ideario de una "infancia indígena lectora", que lee en su propio idioma, porque esa es la lengua del libro que sostiene el niño. El libro que están leyendo es la otra cartilla Lede Na Qom destinada a qom adultos, lo que además nos sugiere una circulación y uso entre todos los grupos etarios del ámbito educativo de la JUM. En términos de representación simbólica, estaría propiciando la construcción de una infancia lectora que lee sus propios "escritos qom". Sin más detalles del contexto, es una escena de lectura que podría tal vez interpretarse como metáfora de una actividad placentera (Cucuzza, 2009), donde los niños son portadores de objetos de la cultura escrita, y leen de manera autónoma y comunitaria un libro.

Desde los contenidos presentes en la cartilla se construye una infancia alejada del "deber ser", es decir, de prescripciones de normas morales y de la conformación de 
Almirón, García y Liva. “Que el qomle’ec, el toba, no es cualquier cosa...”: la enseñanza del qom en e el ámbito...

una identidad nacional que fue una tendencia común observada en los textos escolares de las décadas anteriores (Linares, 2009). Más bien es una infancia de acción y de juegos: "Aunque estoy enfermo es cierto que no tengo miedo. Yo juego"; "Eli ve el loro. Este Eli burla al loro. El loro burla a Elí", que aprende desde la experiencia propia con animales o de intercambio con pares. Son contenidos que permiten construir valores en torno a una relación comunitaria y de cuidado entre la naturaleza y los niños: "El loro es como el animalito de Elena. El animalito es como si fuera el hermanito de Elena"; y de éstos entre sí: "El loro es el animalito de Elena. Eli ve al loro y dice: doy esta cascarita". En esta cartilla, a diferencia de la que continúa, no se encuentran contenidos religiosos. Conjeturamos al respecto que el uso de las historias bíblicas complementaba la incorporación de la temática religiosa a las situaciones de enseñanza destinada a la infancia indígena.

Imagen 6 y 7. Cartilla de alfabetización Elena qataq Eli

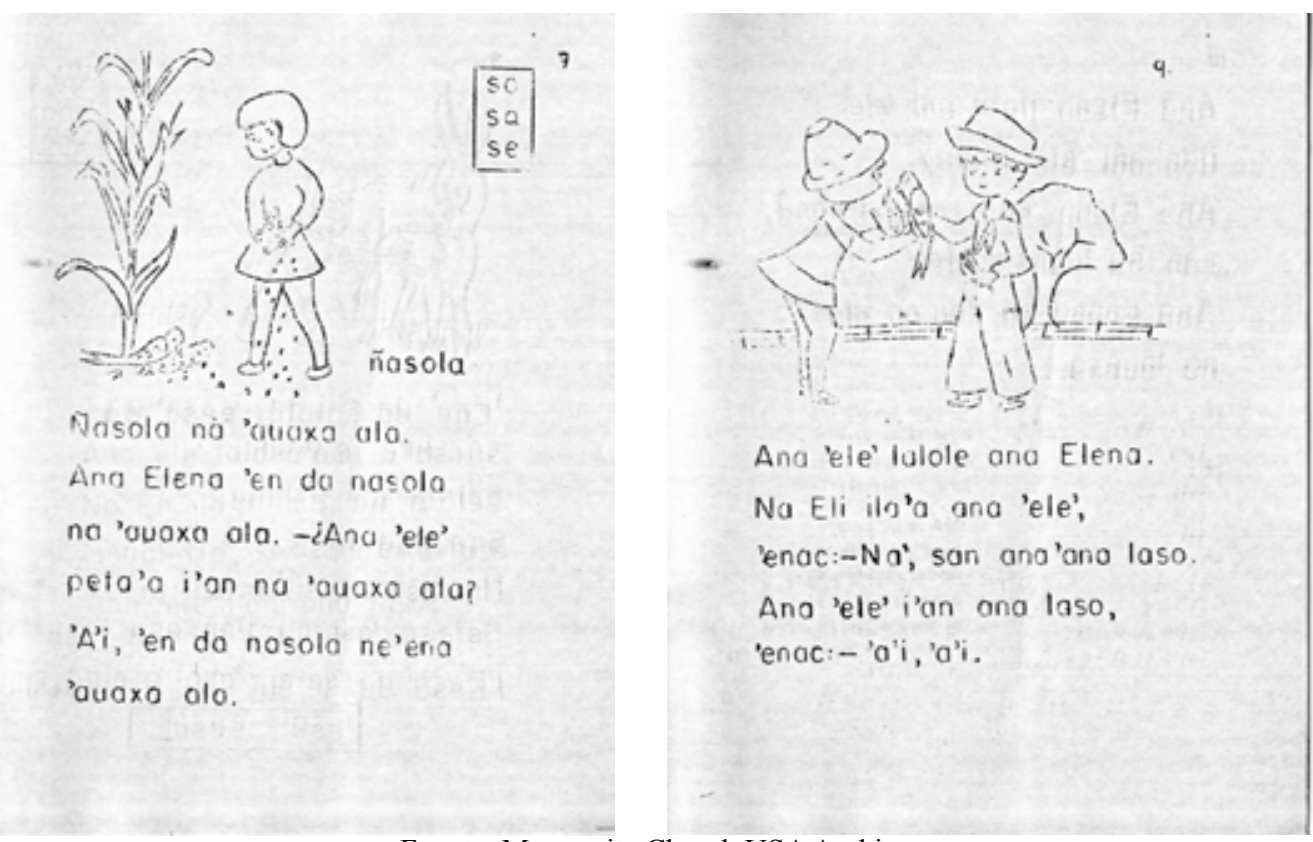

Fuente: Mennonite Church USA Archive.

\section{Lede Qom : La cartilla para adultos}

El título de esta cartilla puede ser traducido al castellano como "Escritos de los Qom”. La portada ilustra una escena de lectura entre dos indígenas, en la cual la disposición de los personajes sugiere que un adulto enseña a leer un texto a un joven. El proceso de producción enunciado donde fue central la participación indígena en su confección, el sentido del título y la escena de lectura disruptiva 
donde un indígena enseña a otro, son indicios del marco ideológico antes reseñado, en el que la apropiación de los qom de la cultura escrita constituye un dato central.

Imagen 8. Cartilla de alfabetización Lede Qom

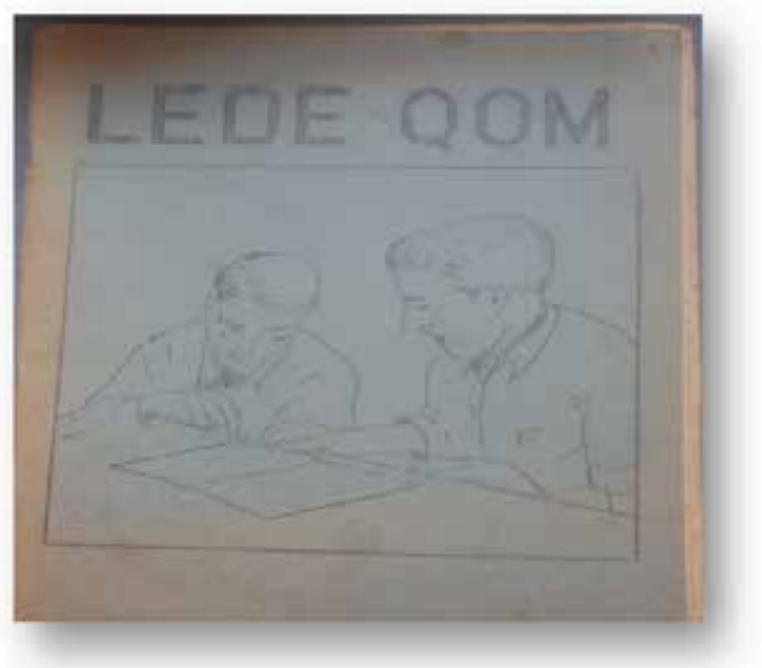

Fuente: Archivo de la Asociación Amigos del Aborigen.

Durante la investigación, hemos identificado un proceso de circulación de la cartilla por la provincia y hallamos otra copia con una parcial modificación lingüística al título: Lede Na Qom. La misma podría estar relacionada con el proceso de escritura y el uso de la cartilla entre otras variedades dialectales del qom. Es también la diferencia observada en la cartilla de los niños, donde fue incorporado el uso del "Na" que sugiere su elaboración posterior.

Siguiendo con esta línea de análisis de aproximación lingüística, otra palabra principal que aparece en la cartilla "Nede" (libro) también nos ofrece indicios sobre los procesos de estandarización de la lengua y sus expresiones al interior de la alfabetización. Sobre el uso de la /d/ en vez de la /r/ en la palabra Nede, varios estudios lingüísticos que cubren variedades de Chaco y Formosa, se han ocupado de este fonema /d/ que también se realiza como vibrante simple [r]. Esta realización, junto con [d], puede ser pensada como variantes facultativas, es decir, como dos sonidos permutables, que pueden aparecer en los mismos contextos, pero que no producen cambio de significado (González, 2015). 
Almirón, García y Liva. “Que el qomle’ec, el toba, no es cualquier cosa...”: la enseñanza del qom en e el ámbito...

Imagen 9. Cartilla de alfabetización Lede Na Qom

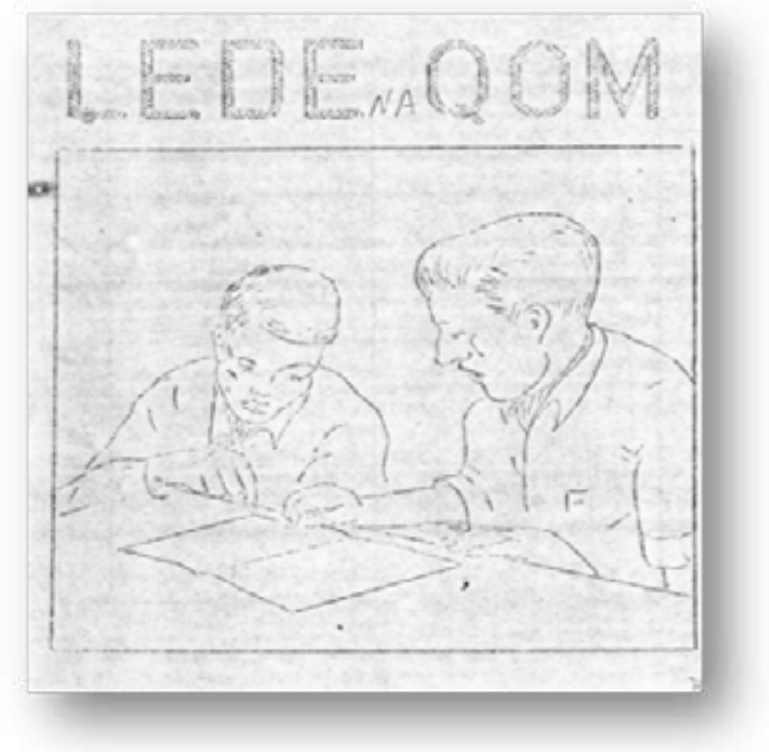

Fuente: Mennonite Church USA Archive.

En términos de discusiones lingüísticas, el sistema fonológico es una construcción de los religiosos que optaron por seleccionar /d/ o /r/ a la hora de armar el sistema de escritura del qom. Siguiendo a Petrucci (2002), nos permite evidenciar las relaciones de poder inscriptas en la escritura, donde se impuso un uso sobre el otro $\mathrm{y}$, en términos más generales la norma, las formas de enseñanza y los usos legítimos en el grupo social. Es decir, además del contexto multilingüe de la alfabetización, es necesario advertir los procesos de estandarización al interior de la lengua qom y las discrepancias suscitadas entre el lenguaje oral y la escritura. La palabra para introducir y reforzar fonológicamente la /d/ en los procesos de enseñanza es Nede:

La cartilla está compuesta de 51 carillas y 28 lecturas. Al igual que la cartilla para la infancia, no presenta referencias de edición o autoría, pero a diferencia de la anterior, este material introducía a la escritura cursiva e imprenta. En cada lectura se recurre al uso de imágenes que representan el tema general abordado. La organización del documento permite inferir la secuencia de enseñanza prevista para la alfabetización: en las siete primeras páginas se presentan palabras generadoras, de las cuales se resalta una vocal. La presentación de las vocales continúa la construcción lingüística del idioma compuesta por la "a, e, i, o".

Desde la página 8 a la 51 se va presentando las 21 consonantes del alfabeto qom, que se asocian a una palabra, luego a una oración y finalmente a un texto extendido compuesto por dos a tres párrafos. Tanto la iconografía como la escritura representan acciones ("está llorando", "corramos", "caminando", "vamos a mi casa"), escenas de la 
vida cotidiana ("me enfermé, estoy enfermo"; "va a llover; está nublado") y del medio circundante del noroeste chaqueño (del "rapiguem", o el oeste, en la toponimia qom que aparece en la cartilla): el monte, el campo, la vegetación (frutos de la recolección como la chaucha del algarrobo), sus usos, costumbres, los trabajos habituales (por ejemplo el tejido con chaguar de las mujeres) y los juegos infantiles. Se incluyen también expresiones qom de la religiosidad como la interpretación de los sueños, y se otorga un lugar sobresaliente a las y los ancianas/os en la transmisión intergeneracional con referencias reiteradas en la cartilla. La apelación al uso del etnónimo es constante, se la puede hallar en varias lecturas. Aparece como palabra generadora en una de ellas, donde se forman expresiones como "Somos qom, ustedes son qom. Hay muchos qom acá. Somos muchos".

Imagen 10. Cartilla de alfabetización Lede Qom

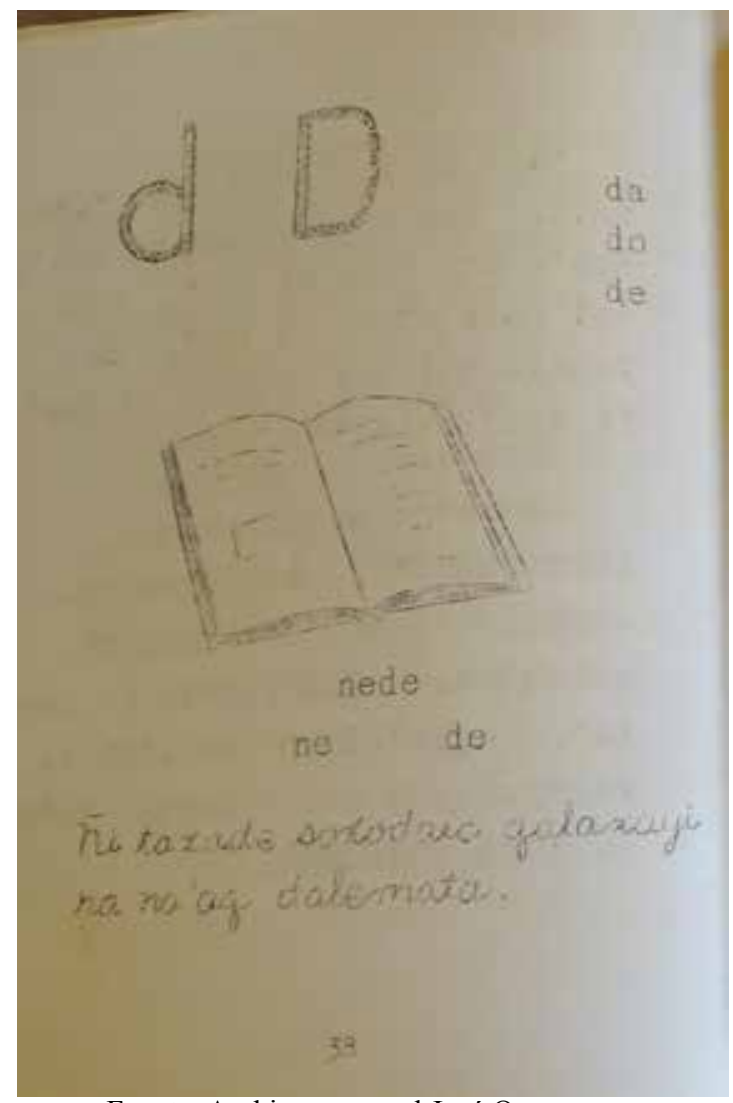

Fuente: Archivo personal José Oyanguren.

Otros contenidos refieren a las transformaciones en los modos de producción y transacción económica de la región con la expansión del capitalismo, por ejemplo, hay una lectura sobre el "algodón", el campo cultivado, la proveeduría, los billetes de banco. Además sobre la enfermedad y los medicamentos de la medicina occidental, y acerca de 
Almirón, García y Liva. “Que el qomle’ec, el toba, no es cualquier cosa...”: la enseñanza del qom en e el ámbito...

bienes culturales objetivados, como es el caso del libro. La lectura de cierre de la cartilla es sobre la difusión del evangelio y su relación con la cultura escrita: la llegada de la Biblia y los himnarios en el tren, que serán repartidos el domingo en la iglesia.

Imagen 11. Cartilla de alfabetización Lede Qom

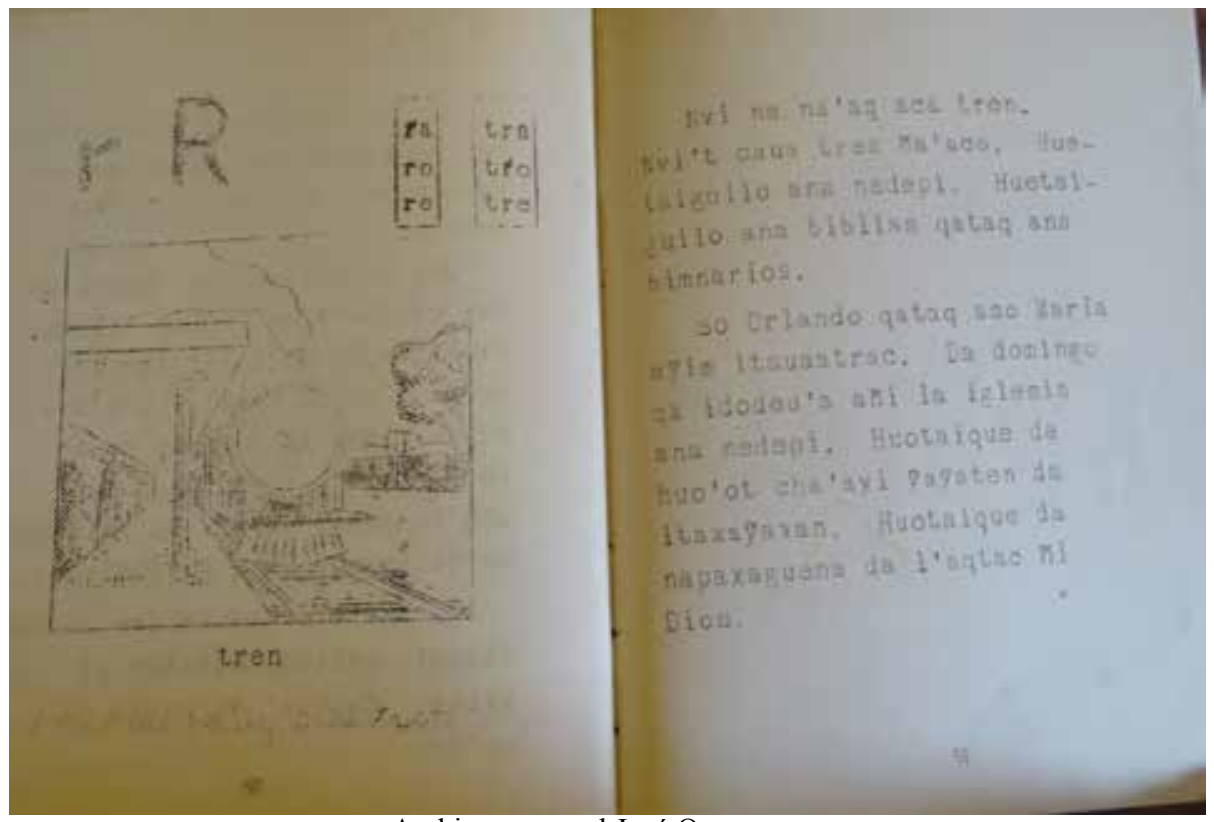

Archivo personal José Oyanguren.

\section{Conclusiones}

El indígena entrevistado Cornelio Castro, quien aprendió a leer y escribir en qom siendo participante de las acciones alfabetizadoras de la JUM, le refirió a su padre un líder religioso y referente destacado de la comunidad en el noroeste chaqueño: "Papá, quiero preguntarte ¿puedo escribir tus relatos cuando vos eras joven? Si escribo lo haré en nuestro idioma" ${ }^{\prime 4}$. En este trabajo, reconstruimos en clave histórica el contexto institucional, las orientaciones de la política de alfabetización y las condiciones materiales que viabilizaron que Castro, así como otros y otras qom de la región, se apropiaran de prácticas de lectura y escritura en el idioma qom. Para ello, recurrimos como fuentes históricas principales al análisis de materiales de lectura utilizados para la enseñanza en el marco de las acciones desarrolladas entre las décadas de 1960-1970 por la misión protestante Junta Unida de Misiones.

Dimos cuenta de cómo las cartillas confeccionadas constituyeron una herramienta pedagógica fundamental para la alfabetización en qom y la apropiación de prácticas de la cultura escrita. Asimismo, en el marco de una política vinculada a la difusión del evangelio, la lectura en el propio idioma representó un instrumento

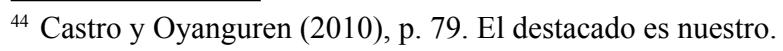


privilegiado para la difusión del evangelio a través de la lectura bíblica en la lengua vernácula. Particularizamos en dos tipos de textos: Elena qataq Eli (Elena y Eli) y Lede Qom (Escritos de los Qom), aunque también presentamos referencias sobre otros que fueron soportes para la enseñanza: glosarios de palabras en qom; series de cuentos clásicos; periódico escolar y láminas; capítulos, versículos o historias de la Biblia.

En tal sentido, en el marco de una política orientada al aprendizaje del idioma nativo, los alfabetizadores dieron prioridad a la elaboración de materiales en qom o bilingües, recurriendo en los procesos de producción a la participación de indígenas letrados y la colaboración lingüística del menonita Buckwalter. Tendientes a generar las condiciones materiales para un acceso extendido dentro de la población alfabetizada, conjuntamente la reproducción y distribución de los textos compuso una de las líneas de esta política. Siguiendo la línea teórica de la historia de la cultura escrita (Castillo Gómez, 2003), este tipo de análisis permitió presentar referencias sobre la disponibilidad de esos materiales, por ejemplo, dónde circulaban y en qué espacio se leían normalmente (ámbito educativo), quiénes establecían los contenidos y controlan su lectura (una participación predominante de las y los alfabetizadores).

Asimismo, contribuye al campo permitiendo analizar las formas particulares que asumió la relación de los qom con la cultura escrita en este periodo y contexto local; una temática escasamente explorada en la bibliografía especializada. En referencia al idioma de enseñanza, permitió problematizar los sentidos divergentes que adquirió en un mismo ámbito la enseñanza bilingüe, donde fueron concurrentes el desarrollo de una política integracionista con la puesta en valor del idioma nativo en tanto diacrítico identitario.

En los dos últimos apartados, fueron descriptas las características de las cartillas de alfabetización que también permitieron acercarnos al entorno más general de los procesos de enseñanza. Señalamos un predominio de combinación del uso de imágenes y de textos escritos en qom. Las imágenes funcionaban como un refuerzo gráfico de los contenidos incluidos y constituyeron una estrategia pedagógica primordial en un contexto multilingüe, donde circulaban, cuando menos, dos idiomas diferentes (qom y castellano). Al mismo tiempo, se observan figuras, palabras o construcciones gramaticales referidas a plantas, animales, personas (niños, adultos o un/a anciana/o qom), objetos (libro, sombrero, aguja con hilo) o situaciones que describen acciones o acontecimientos (una niña que juega, un adulto que tuvo un sueño, una anciana qom tomando mate). Es decir, eran de uso cotidiano en la realidad social y cultural circundante de los qom participantes.

Queremos cerrar este trabajo con el relato retrospectivo de uno de los alfabetizados, Cornelio Romero, quien en una entrevista recordaba leer de manera individual lecturas en qom en el espacio educativo de la misión protestante, otorgándole una significación importante y puesta en valor al uso del idioma nativo para la construcción de una identidad étnica en tanto diacrítico identitario: "entonces ese era el enfoque mucha más de los textos, que el qomle 'ec, el toba, no es cualquier cosa" "45.

\footnotetext{
${ }^{45}$ Entrevista a Cornelio Romero, diciembre de 2017.
} 
Almirón, García y Liva. “Que el qomle’ec, el toba, no es cualquier cosa...”: la enseñanza del qom en e el ámbito...

\section{Fuentes escritas}

Buckwalter, A. (20 de marzo de 1965). El Chaco Argentino. Collection: "Albert S. and Lois Buckwalter Papers, 1949-2004". Mennonite Church USA Archive, Illinois.

Castro, C. y Oyanguren, J. (2010). Da na'aqtaguec so Ceferino Castro. Chaco: Ediciones Sayaten.

Consejo de Misiones y Avance. (Agosto de 1965). Carta a los pastores de las Iglesias Metodistas de Argentina. Colección Obispo Sante Uberti Barbieri. Archivo Histórico "Esther Gattinoni de Regueira", Colegio Ward, Buenos Aires, Argentina. Consejo de Misiones y Avance. (12 Julio de 1966). Informe a la Junta General. Colección Obispo Sante Uberti Barbieri. Archivo Histórico "Esther Gattinoni de Regueira". Colegio Ward, Buenos Aires, Argentina.

Consejo de Misiones y Avance. (Septiembre de 1968). Situación de la obra misionera entre los Tobas. Junta Unida de Misiones. Colección Obispo Sante Uberti Barbieri. Archivo Histórico "Esther Gattinoni de Regueira", Colegio Ward, Buenos Aires, Argentina.

Elena qataq Eli. (S/f). Cartilla de alfabetización. Collection: "Albert S. and Lois Buckwalter Papers, 1949-2004”. Mennonite Church USA Archive, Illinois, EEUU. Iglesia Metodista. Actas Oficiales de la Septuagésima Quinta Reunión de la Conferencia Anual en la Argentina (1967). Acta de Constitución de la Junta Unida de Misiones. Colección Obispo Sante Uberti Barbieri. Archivo Histórico "Esther Gattinoni de Regueira", Colegio Ward, Buenos Aires, Argentina.

Lede NA Qom. (s/f). Cartilla de alfabetización. Collection: "Albert S. and Lois Buckwalter Papers, 1949-2004”. Mennonite Church USA Archive, Illinois, EEUU.

Lede Qom. (s/f). Cartilla de alfabetización. Archivo de la Asociación Amigos del Aborigen. Chaco, Argentina.

Lede Qom. (s/f). Cartilla de alfabetización. Archivo personal de José Oyanguren.

Reivindicación. Órgano indigenista chaqueño. Octubre de 1958. Año II, №131958, p.3. Archivo de la Asociación Amigos del Aborigen, Chaco, Argentina.

Ortega, H. (septiembre de 1968). Carta a los pastores, juntas oficiales y miembros de la Iglesia Metodista en Argentina. Colección Obispo Sante Uberti Barbieri. Archivo Histórico "Esther Gattinoni de Regueira", Colegio Ward, Buenos Aires, Argentina. Ortega, H. (1966). Operación Toba. Colección Obispo Sante Uberti Barbieri. Archivo Histórico "Esther Gattinoni de Regueira", Colegio Ward, Buenos Aires, Argentina.

S/a. (octubre de 1966). El Estandarte Evangélico. Archivo Histórico "Esther Gattinoni de Regueira". Hemeroteca. Colegio Ward, Buenos Aires, Argentina.

Palaci, E. y Peiró, Á. (1968). Recomendaciones de la consulta sobre la obra misionera entre los Tobas. Colección Obispo Sante Uberti Barbieri, Archivo Histórico "Esther Gattinoni de Regueira", Colegio Ward, Buenos Aires, Argentina.

UNESCO. (diciembre de 1960). Convención relativa a la Lucha contra las Discriminaciones en la Esfera de la Enseñanza.

\section{Fuentes orales}

Bendetto, Carlos. [alfabetizador de la JUM]. (Septiembre de 2011). Entrevista Autor [cinta de audio]. Juan J. Castelli, Chaco. 
Castro, Cornelio. [indígena qom]. (Diciembre de 2015). Entrevista Autor [cinta de audio]. Juan J. Castelli, Chaco.

Celín, José. [indígena qom]. (Diciembre de 2015). Entrevista Autor [cinta de audio]. Juan J. Castelli, Chaco.

Dalma, Mabel y Collet, Jorge [referentes JUM]. (septiembre de 2011). Entrevista de Autor [cinta de audio]. Resistencia, Chaco.

Inderecio, Beatriz. [indígena qom]. (Diciembre de 2015). Entrevista Autor [cinta de audio]. Barranqueras, Chaco.

Romero, Cornelio. [indígena qom]. (Marzo de 2017). Entrevista Autor [cinta de audio]. Juan J. Castelli, Chaco.

Sotagag, Genaro. [indígena qom]. (Marzo de 2017). Entrevista Autor [cinta de audio]. Juan J. Castelli, Chaco.

Vossler, Olga [alfabetizadora JUM]. (Marzo de 2017). Entrevista Autor [cinta de audio]. Resistencia, Chaco.

\section{Referencias bibliográficas}

Almiron, V. (2019). Historia de apropiación de la cultura escrita entre qom del noroeste del Chaco (1960-1976). Tesis Doctoral. Paraná: Universidad Nacional de Entre Ríos.

Almiron, V. y Padawer, A. (2020). "Escrituras (de) qom en el dominio religioso (Chaco argentino, 1950-1970)". Tellus, Año 20, № 43. Recuperado de: https://tellusucdb. emnuvens.com.br/tellus/issue/view/46 DOI: https://doi.org/10.20435/tellus.v20i43.703

Almiron, V.; Padawer, A.; Artieda, T. (2017). "Políticas y prácticas de alfabetización para Qom en una misión protestante (Argentina, Chaco. 1964-1973 circa)". Historia de la Educación. Anuario de la Sociedad Argentina, Vol. 18, № 2, pp. 251-271. Recuperado de: http://ppct.caicyt.gov.ar/index.php/anuario/article/view/10410 //

Artieda, T. (2012). Historias indígenas de acceso a la lectura y la escritura en tres ámbitos, religión, familia, escuela (1914-1960 circa). Cucuzza, H. y Spregelburd, R (cord.): Historia de la lectura en la Argentina: del catecismo colonial a las netbooks estatales. Buenos Aires: Editoras del Calderón. Pp. 435-470.

Cucuzza, H. (2009). Retórica de la escena de lectura en las carátulas del libro escolar. En P. Spregelburd \& C. Linares, (org.). La lectura en los manuales escolares, (pp. 13-29). Buenos Aires: Departamento de publicaciones e imprenta de UNLu. Universidad Nacional del Lujan e Universidad Nacional del Nordeste.

Chartier, R. (2005). El orden de los libros. Lectores, autores, bibliotecas en Europa entre los siglos XIV y XVIII. Barcelona: Gedisa.

Chartier, R. (1999). Cultura escrita. Literatura e historia. Conversaciones con Roger Chartier. México: Fondo de Cultura Económica.

Escalante Fernández, Carlos (2014). Mazahuas, campesinos y maestros. Prácticas de escritura, tierras y escuelas en la historia de Jocotitlán, Estado de México (18791940). Toluca: El Colegio Mexiquense. 
Almirón, García y Liva. “Que el qomle’ec, el toba, no es cualquier cosa...”: la enseñanza del qom en e el ámbito...

Escalante Fernández, Carlos (2013). Las cartillas de alfabetización de la campaña de alfabetización de 1944-1946 en México. Revista Mexicana de Historia de la Educación. Vol. I, N¹, pp. 155-162. DOI: https://doi.org/10.29351/rmhe.v1i1.16

Gilmont, J.F. (1998). "Reformas protestantes y lectura”. En G. Cavallo \& R. Chartier (coord.). Historia de la lectura en el mundo occidental, (pp. 329-366). Madrid: Taurus.

González, R. (2015). Estudio fonológico y morfosintáctico de la lengua toba hablada en el este de la provincia de Formosa (Argentina). LINCOM Studies in Native American Linguistics, Recuperado de: https://journals.openedition.org/ jsa/15008?lang=es ; DOI: https://doi.org/10.4000/jsa.15008.

Goody, J. (comp.) (1996). Cultura escrita en sociedades tradicionales. Barcelona: Gedisa. Hermitte, E. (1995). Estudio sobre la situación de los aborígenes de la Provincia del Chaco y políticas para su integración a la sociedad nacional. Misiones: Editorial Universitaria. Vol. I, II y III.

Lévi-Strauss, C. (1964). El pensamiento salvaje. México: Fondo de Cultura Económica. Linares, C. (2009). "Los libros de lectura en la Argentina, sus características a lo largo de un siglo". En P. Spregelburd \& C. Linares, (org.). La lectura en los manuales escolares, (pp. 47-57). Buenos Aires: Departamento de publicaciones e imprenta de UNLu. Universidad Nacional del Lujan e Universidad Nacional del Nordeste.

Lyons, M. (2012). Historia de la lectura y de la escritura en el mundo occidental. Buenos Aires: Editoras Del Calderón.

McLuhan, M. (1969). La Galaxia Gutenberg. La formación del homo tipográfico. Madrid: Aguilar. Primera versión al castellano.

Neumann, E. (2015). Letra de índios: cultura escrita, comunicação e memória indígena nas Reduções do Paraguai. São Bernardo do Campo: Nhanduti. Florianópolis, Brasil, del 27 al 21 de julho.

Ong, W. (1987). Oralidad y escritura. Tecnologías de la palabra. México: Fondo de Cultura Económica. Primera edición en español.

Petrucci, A. (2002). Armando: Un paseo por los bosques De la escritura/ Entrevistado por Castillo Gómez, A., En LITTERAE. Cuadernos sobre Cultura Escrita, $\mathrm{N}^{\circ} 2$, pp. 9-37, Recuperado de: https://e-archivo.uc3m.es/handle/10016/2295

Rockwell, E. (2008). Relaciones con la cultura escrita en una comunidad nahua a principios del Siglo XX: Temas recurrentes. Revista Lingua Escrita. N$^{\circ} 4$. pp. 1-17.

Rockwell, E. (2006). Apropiaciones indígenas de la escritura en tres dominios: Religión, Gobierno y Escuela. Cultura Escrita \& Sociedad. No 3, pp. 161-218.

Rockwell, E. (2004). "Entre la vida y los libros: prácticas de lectura en las escuelas de la Malintzi a principios del siglo XX". En C. Castañeda García, L. Galván Lafarga y L. Martínez Moctezuma (coord.): Lecturas y lectores en la historia de México, (pp. 327-358). México: CIESAS: El Colegio de Michoacán: Universidad Autónoma del Estado de Morelos.

Rockwell, E. (2001). La lectura como práctica cultural: conceptos para el estudio de los libros escolares. Educação e Pesquisa, Recuperado de: https://www.scielo.br/ scielo.php?pid=S151797022001000100002\&script=sci_arttext\&tlng=es; DOI: https://doi.org/10.1590/S1517-7022001000100002 